\title{
New Investment Models for Broadband in Denmark and Sweden
}

Morten Falch, Anders Henten, Reza Tadayoni and Idongesit Williams

CMI Aalborg University Copenhagen, Denmark

E-mail: $\{$ falch; henten; reza; idong $\} @$ cmi.aau.dk

Received 29 June 2015;

Accepted 17 December 2015

\begin{abstract}
The aim of this paper is to analyse whether the developmental policy model applied for fibre roll-out in Sweden can be used as inspiration for the Danish telecom policy. This is done through a comparison of the two very different policy approaches applied in Denmark and Sweden. A case study on public intervention in the rural Swedish municipality of Almhult is included to illustrate the Swedish model.
\end{abstract}

Keywords: broadband policy, regulation, developmental policy, public private partnership.

\section{Introduction}

In the past decade, it has been realized that market liberalization initiatives have been unable to create sufficient investments in network facilities (Melody, 2013). Especially in rural areas public initiatives are needed, if the objectives of full broadband coverage are to be achieved. The idea of liberalization has certainly not been abandoned, but the latest developments in putting public money into the extension of broadband infrastructures could well be interpreted as a degree of distrust in the ability of market forces to deliver in terms of a universal broadband infrastructure.

Journal of NBICT, Vol. 1, 1-18.

doi: 10.13052/NBICT.2016.001

(c) 2016 River Publishers. All rights reserved. 


\section{M. Falch et al.}

This is the background for an increasing focus on new investment models for network expansion, where the public sector plays an active role in infrastructure development either through funding or by assuming an initiating or coordinating role. In order to minimize market distortion policy tools like public private partnerships, where private companies are involved in the implementation, have received renewed attention.

The aim of this paper is to discuss whether there is a role to play for this kind of policies in a mature telecom market like Denmark, and if Denmark can learn from in the Swedish experiences in this regard. This is done through a comparison of telecom policies and performances in Denmark and Sweden.

Denmark and Sweden are both among the highest ranking countries with regard to broadband access. However, the strategies they have applied are very different, especially with regard to their use of public private partnerships and public funding. Denmark has until recently maintained a regulatory approach with an active regulation of a fully liberalized telecom market, while public entities in Sweden directly have intervened much more directly on the telecom market. However, there are signs of a shift in the Danish approach towards broadband development, and public funds are being allocated for investments in rural areas. In this way Denmark follows general European trend where the public sector plays a more active role. Based on a case study on the Swedish experiences, this paper discusses the perspectives and practical implementation of such a policy.

Section 2 provides an introduction to the regulatory and developmental approach to telecom policy, while Section 3 links the developmental approach to the concept of PPP. Sections 4 and 5 describe how these approaches have been applied in Denmark and Sweden, and the conclusion discusses possible implications of the Swedish approach for Danish telecom policy.

\section{Regulation versus Facilitation}

The two different investment models applied in Denmark and in Sweden can be described as a regulatory and a developmental approach. This distinction is inspired by Chalmers Johnson (1982) and by Giandomenico Majone (1997). In his book on the Japanese post-war miracle, Johnson introduced the concept of the developmental state as opposed to the regulatory state. According the Johnson, the role of the state bureaucracy in a developmental state includes 'first, to identify and choose the industries to be developed (industrial structure policy); second to identify the best means of rapidly developing the chosen industries' (Johnson, 1982). The developmental state is contrasted with the 
regulatory state, where the state is mainly concerned with facilitating economic competition, but not with direct intervention in substantive matters.

Within the EU, the regulatory and the developmental state have been connected to two different streams of policy initiatives. The first stream focuses on reforming the telecom service industry through implementation of a series of regulatory packages, while the second stream has a broader perspective, as it includes the entire ICT ecosystem. This stream includes a series of consecutive development plans such as e-Europe, i2010 and "Digital Agenda for Europe a Europe 2020 initiative".

The objective of a regulatory approach to telecom policy is to create a stable policy framework for a liberalized telecom market with real competition. The instruments in this approach are rulemaking and correction of market failures. However direct market interventions are to be avoided. This approach is theoretically supported by mainstream economics. The argument is here that a stable regulatory environment reduces transaction costs and stimulates investments (Spiller \& Tommasi, 2008).

The developmental approach is to stimulate investments and the use of ICT through various public sector initiated activities. The instruments applied could be demand stimulation via public consumption or subsidies to use or supply ICT services. This includes direct market intervention e.g. in the form of public private partnerships providing public support to infrastructure development. This approach is supported by (Stiglitz, 1998) and in line with the concept of the developmental state (Johnson, 1982).

The policy tools connected to each of the two approaches are depicted in Table 1 below.

According to Giandomenico Majone (Majone, 1997) the EU countries have changed their mode of governance in the direction of a regulatory mode of governance. This is partly a response to the creation of the internal European market. The creation of the internal market has demanded a harmonization of

Table 1 Regulatory and developmental policy tools

\begin{tabular}{ll}
\hline Regulatory & Developmental \\
\hline - Improvement of framework conditions & - Facilitating economic growth \\
- Focus on promotion of competition & - Guideposting \\
- Rulemaking is the primary remedy & - Direct intervention in the market \\
& - Financing and tax incentives \\
& - PPP \\
\hline
\end{tabular}

Source: With inspiration from Majone (1997). 
regulation across borders and has left less room for developmental policies at the national level. The implications of this at the telecom markets was the implementation of regulatory telecom packages, which emphasized on promotion of competition.

In spite of its indisputable success, the EU telecom reform has been insufficient to facilitate investments in broadband infrastructures at an adequate level (Melody, 2013) and this has led to an increasing focus on developmental policy tools such as Public Private Partnership (PPP).

\section{Public Private Partnership Models in the Telecom Sector}

Public private partnership (PPP) is often used a framework for organizing government and business relations (Helby Petersen, 2010). Since the 1980s, many different types of public sector activities in Europe, which formerly were produced in-house, have been outsourced to private companies through public procurement or relational contracting. One of the areas in particular, where the PPP model have important, is in organizing and funding of major construction and infrastructure projects (Helby Petersen, 2011).

Within the telecom sector the direction is the opposite, since PPP here is used as a model for public involvement in an area dominated by the private sector (Falch \& Henten, 2010).

Since the wave of liberalization in the telecommunications area began in the 1980s, investments in telecommunications infrastructures have mainly been seen as the responsibility of commercial operators. In this situation, PPP implies public sector involvement in activities, which currently are outside the scope of the public sector. The purposes of a PPP arrangement can in this case be to promote public sector objectives such as regional development and enhancement of ICT competencies.

Three different types of PPP projects can be distinguished within the area of ICT:

- PPP as a tool for development broadband infrastructures (optical or wireless)

- PPP applied for stimulation of service development

- Integrated projects including investments in ICT, where PPP facilitates broader development objectives.

A PPP project will usually imply a contractual relationship between a public sector agency and a private company. However, public authorities can facilitate 
ICT development without engaging in such a relationship. In this case the concept of Public Private Interplay (PPI) may be a more useful concept to apply (Barroso and Feijoo, 2010).

A special variation of PPP is public-private community partnership (PPCP) in which the local community is also one of the partners involved (Van Dijk, 2008). PPCP is a way to activate local resources and ensure a local foundation and focus on local development rather than profitability as the only parameter of success (Dreier, 1996).

Market distortion is a major concern for projects involving any kind of public support. This is an issue that has been addressed by the European Commission (Falch and Henten, 2008) by definition of white, grey and black geographical areas. White areas are defined as areas without broadband access. In grey areas broadband is provided, but only from one provider. Black areas are those with a broadband market with at least some competition (two or more providers). Only in white areas are state aid in general allowed, while permission of state aid in grey areas depends on an individual assessment.

One way to limit market distortion (and to ensure permission from the Commission) is to grant open access to facilities and services involved in the project.

PPP projects can also be characterized by the level and kind of public involvement. Public authorities can provide other kinds of support than financing (ITU, 2013). For instance can a public authority develop a detailed requirement specification of user needs to be fulfilled and technologies to be applied or they can apply a more technology neutral approach with financial support to projects designed by a private partner.

Ownership of a completed project can be either fully private, fully public or a joint venture. (Lattemann et al, 2009) distinguishes between three different types of institutional arrangements:

1. operator model;

2. concession model; and

3. co-operation model.

In the operator model the public entity assumes responsible for providing services to the citizens, but at least a part of the operations are out-sourced to private partners. In the concession model the private partner(s) takes over the full responsibility and the holds the contact to customers directly. In the co-operation model the responsibility is given to a corporation with involvement of both public and private partners. In broadband projects different models can be applied for provision of infrastructure and for provision of 
services. For example can the public actor be responsible for providing the infrastructure, while service provision is left to private operators.

\section{Regulatory Approach in Denmark}

The Danish telecom market is considered as relatively advanced, and Denmark has for decades ranked among the highest in terms of infrastructure investments and broadband access. This position has been challenged within the past couple of years especially with regard to the penetration of high speed broadband connections. Denmark has had the highest penetration of fixed broadband among OECD countries for many years - and still it ranks as number 2 among OECD countries with a fixed broadband penetration of 41.3 per 100 inhabitants in 2014 (OECD Broadband portal, February 2016).

In the early phase of liberalization, the Danish market was among the most competitive in Europe. Since then the incumbent operator TDC has been able to consolidate its position with high market shares on all platforms for broadband services, and today Denmark is one the countries with least competition on the market for fixed broadband services. Only in Luxembourg and Cyprus has the incumbent a higher market share than Denmark in provision of fixed broadband services (Digital Agenda, 2015).

Coverage of fixed broadband services is close to $100 \%$ and it is estimated that $70 \%$ of the households are able to get connected to an infrastructure, which can provide at least $100 \mathrm{Mbps}$. This is mainly due to a recent upgrade of the cable network to provide DOCSIS 3.0 (Danish Business Authority, 2013). The ambition of the Government is that $100 \mathrm{Mbps}$ download and $30 \%$ upload should be available for everybody in 2020. The cable network does not cover the entire country and substantial investments in network facilities e.g. fibre must be made, if this level of coverage is going to be achieved. It has been suggested to use LTE or other wireless solutions to supplement the fibre infrastructure in certain rural areas, but consumer associations, among others have raised concerned on whether this solution will be able to provide an adequate level of service in the long run.

Coverage of fibre is well above the European average but far from the levels in Japan and Korea, and both Sweden and Norway are in spite of their less favourable environment also somewhat ahead of Denmark. Fibre has in Denmark mainly been promoted by energy companies. Especially Syd Energy (SE) covering southern parts of Denmark have invested heavily in fibre networks. 
TDC's presence at this market is mainly due to their acquisition of a fibre network covering the capital region created by the largest energy provider in Denmark DONG.

Before the mid 1990's Danish telecom market was dominated by the government controlled incumbent operator TeleDanmark, which had a legal monopoly. Danish telecom policy was at this point formed in a close interaction between the Ministry of Transport and the public appointed board of directors in TeleDanmark. The policy in this period was facility based in the sense that there was more emphasis on direct intervention than on market regulation, and Denmark was reluctant towards the liberalization moves suggested by the EU.

In the 1990's ICT came on the political agenda and a telecom was moved to a new ministry for IT and research and a new approach to telecom policy was adopted. The new strategy was to be in the forefront with regard to liberalization in order to attract foreign investments in the sector, the telecom market was totally liberalized already in 1996 - one and a half year ahead of the deadline set by the EU Commission.

This philosophy was labelled "Best and cheapest through real competition" and was the basis for a political agreement made in in 1999, which still defines the framework for current policy initiatives.

A cornerstone in this policy was that no public funding of infrastructure investments should be made. On the other hand the newly established Danish Telecom Agency had a strong commitment towards securing competition from new entrants. Denmark had for a long period a "best practice" clause that ensured that Danish interconnection rates always were among the cheapest in Europe. Denmark was also among the first countries to demand unbundling of the local loop.

As noted above this policy has been successful as the Danish telecom market has performed well on most indicators. However, concern has been raised that development of fibre based networks is too slow. Investments in telecom facilities have declined by one third since 2008, in 2013 the investments were at the lowest level for ten years, and there was no improvement in 2014 (Danish Energy Agency, 2015). The energy companies have for obvious reasons argued that the fibre based network infrastructure needs to be expanded at a more rapid pace. Especially in rural areas, there is a risk that lack of access to adequate telecom facilities may hamper social and economic development.

For this reason it is being discussed how the state can facilitate infrastructure investments by assuming a developmental role in addition to its role as regulator. Several parties have for different reasons argued that it is time 
to revise the 1999 agreement and provide more room for public initiatives. This has been supported by the consumer association and the Danish Energy Association.

In a series of interviews conducted with players on the Danish telecom market $^{1}$ the general assessment was that regulation overwhelmingly is the main public policy approach for developing the telecom infrastructure - and that it should be so. It was, nevertheless, noted that developmental elements in terms of public support for infrastructure development have entered more forcefully policy discussions in the telecom field in the last few years. The general opinion is that developmental policies should focus primarily on the demand side - as has been the Danish policy approach during the past 20 years. The well-known topic of service and infrastructure competition is also part of the discussion. This can be a purely regulatory issue, but can also include developmental elements concerning public support for infrastructure development. However, none of the interviewees favour extensive public economic funding, but some of the interviewees would favour more focus on infrastructure competition and less on service competition.

Considering policy discussions and the number of programmes offering support for infrastructure development in other EU countries as well as in other regions, it might come as a surprise that direct support to the supply site was hardly mentioned. Public support was mentioned only in relation to introduction of reverse auctions in order to secure investments in rural areas and was only mentioned by one actor. A concession model using reverse auctions is here seen as a way to provide public funding, where the distortion of the free market mechanism is minimized.

A more active role to be played by the municipalities was suggested. Municipalities should become more active in the design of local infrastructure projects and be allowed to provide credit facilities if needed, but no direct funding should be provided.

When it comes to the need for universal access to a fibre based infrastructure, there were different opinions. Some of the interviewees see universal access to fibre as a major success criterion, while others see wireless infrastructures such as LTE and high speed cobber services as adequate alternatives. Most players have no special interest in the specific kinds of technologies applied for providing telecom services. Still, the question regarding the need for fibre is a crucial one, as it has implications for the kind of companies dominating infrastructure and service provision in the future.

${ }^{1}$ For more details see (Henten \& Falch, 2014). 
In February 2013 a first developmental initiative was taken; when it was decided provide public funding for broadband investments on Bornholm (a small isolated island in the Baltic Sea). It was emphasized that it was an exceptional initiative, which would not be repeated elsewhere, but it has been followed by other (although less generous) initiatives, and it can be seen as a first step towards a more active public participation in telecom infrastructure development.

A credit facility has been established in order to allow municipalities to initiate broadband projects in their area, and it has been suggested to further increase the scope of this kind of municipality led activities. In this case the principle that infrastructure development should be market based is maintained, as funds are provided as a credit only.

The present Government has taken this a step further, as they have setup a broadband fund of 300 million DKK (app. 40 million EURO) over four years, in order to promote rural coverage of broadband. It is the ambition to finance such a fund by revenues collected from spectrum auctions. It is estimated that only around 10,000 citizens are considered to be unable to get an Internet connection good quality. The initiative is quite new, and the procedures are not worked out in detail, but it seems that support can be provided to enterprises as well as local community organisations in relevant areas.

\section{Developmental Approach in Sweden}

Sweden has a penetration of broadband of 33.3 per 100 inhabitants, which is slightly above the OECD average. However they are in the top when it comes to penetration of fibre connections and high speed broadband.

Due to the size of the country, the challenge of full coverage is far greater than it is in countries like Denmark. With regard to full coverage Sweden is therefore less ambitious than Denmark. The aim is here a $90 \%$ coverage of $100 \mathrm{Mbit} / \mathrm{s}$ in 2020, while Denmark aims for a 100\% coverage (Regeringskanseliet, 2014).

The Swedish broadband market is more competitive than the Danish. For fixed broadband connections the market share of the incumbent operator Telia is as low as $37 \%$ (compared to the TDC market share of $61 \%$ ), and this is among the lowest in the OECD.

Sweden has a long tradition for a strong regional policy focus and direct public involvement in development of ICT infrastructures. In 1999/2000 the Swedish Government adopted a broadband policy, which included substantial public support to infrastructure development. The financial support included 
$€ 280$ million to a national operator-neutral backbone, €358 million to municipalities to develop access and $€ 290$ million to regional networks and to create local infrastructure plans (Forzati and Mattsson, 2014).

The public involvement goes beyond the mere financial support and today 175 out of 290 municipalities have deployed their own fibre networks (Forzati and Mattsson, 2014). Many of these municipalities are located in the sparsely populated northern Sweden. It should however be noted that the public involvement goes beyond the rural areas. In fact one of the first fibre projects was initiated in the city of Stockholm in 1994 with the formation of Stokab. Stokab was formed as a public company with the purpose of rolling out a dark fibre operational network (Van der Wee et al, 2011), and is still in operation. In the case of Stokab a kind of PPP co-operation model is applied, as Stokab only provide the dark fibre, while service provision is left to private operators.

\subsection{A. Almhult - An Example of a Rural PPP Project}

A recent example of a PPP fibre project can be found in Almhult. Almhult municipality is the home of 16000 inhabitants. More than half of the population lives in the town of Almhult. The land size is 891 square $\mathrm{km}$. In 2010, the Almhult municipality in the Kronoberg country of Sweden decided to extend fibre optic connectivity to municipality offices within the municipality. The municipality was inspired to expand the connectivity to people's private homes within their jurisdiction. The idea was to facilitate cooperatives that will organize people in various areas of the municipality to facilitate the extension of the fibre optics infrastructure. The Gateway to Almhult was Tele2. Tele2's principal client was IKEA in Almhult. The backhaul of the network is the municipality built backbone. The Access network is the cooperative owned fibre optic network.

The municipality's plan involved the demarcation of the municipality along the lines of the old church governance system, parishes. The residents of each of the nine parishes were to organize themselves into broadband cooperatives. The executives of the parishes would then work in conjunction with the municipality. Each parish would facilitate the deployment of fibre optics in their parish, interconnecting with the municipality fibre optic infrastructure. The coops primary duty in the process was the mobilization of users and the digging for the laying of the fibre-optic infrastructure.

The municipality held information meetings in order to facilitate the forming of local cooperatives, which could invest in fibre networks. The 
municipality acquired the necessary equipment needed and sold it to local co-operatives. The municipality has also provided technical support and contact to an entrepreneur, who could build the network. Construction, operation and maintenance are out-sourced to a private operator, but the municipality keeps the ownership of the backbone network.

The municipality has provided $€ 5$ million for financing the expansion of municipality network, but the access network extending the coverage to include the parishes was to be financed by the local cooperatives. However, $50 \%$ of the costs were covered by EU regional funds administered by the regional council. Still the costs to be paid by each household amounts to $€ 2500$ in installation fee.

The provision of a service platform has been outsourced to a private operator through a public tender organized by the municipality. The platform should include at least 5 Internet Service Providers (ISPs), 2 IPTV providers and 5 IP telephone providers. Zitius a broadband infrastructure provider won the bid to manage and operate the infrastructure. Quadracom, a sister company to Zitius provided the Broadband service briefcase.

In spite of the high installation costs the service uptake has been high. One reason for this is the lack of decent alternatives in the rural areas. The incumbent operator Telia is not obliged to maintain the old cobber based network. In 2005 a major storm destroyed most of the telephony infrastructure in some parts of the municipality. Telia was not willing to re-establish the old network and the wireless alternative did not work properly. Therefore the rural population does not have a choice if they want to stay connected - even if they just want an ordinary phone connection.

The chosen PPP model may have had a positive impact on the take-up as well. The model is a co-operation model, but it differs from the one applied in the Stokab case, as it involves the local community. The local community is involved not just in financing, but also in planning, implementation and operation of the network. The project is led by the local community, and the role of the municipality is more as a facilitator than as a partner, although a part of the core network is owned by the municipality.

\section{Conclusion}

Denmark and Sweden have both been successful in stimulating telecom investments, and both countries are among those with the best broadband infrastructures. Denmark has the highest penetration of broadband, but in Sweden the use of fibres is more widespread and connections provided are of 
a higher speed. Denmark is a small densely populated country, while Sweden has large sparsely populated rural areas. In spite of this challenge, Sweden has obtained a high level of rural coverage, and the penetration of optical fibres is much higher than in Denmark.

In order to improve rural communication facilities, Denmark has recently introduced a number of developmental initiatives, which are foreign to the Danish tradition with focus on regulation of the free market and with limited public involvement. It is therefore obvious to discuss whether Denmark can learn from the approach taken in Sweden.

Can we then conclude that the Swedish approach has been more successful? Not necessarily. It is of no surprise that the penetration of fibres increases, if the public sector provides financial support or makes its own investments. The question is whether the objective of providing high speed broadband services for all can be met by using less intrusive and cheaper policy tools.

This leads to at least three sub questions: Crowding out: Do the public initiatives replace private investments fulfilling similar objectives? Technology neutrality: Does it make sense to focus on fibre based solutions only? And finally: If public support to infrastructure development should be provided, which model should then be applied? These questions cannot be answered in general, but must be related to the specific environment of each project.

There are certain areas where it is very difficult to imagine any infrastructure investments made by private operators without any kind of public support, and there is more of this kind of areas in Sweden than in Denmark. The crowding out effect does also depend on the institutional setup for the public intervention, and the level of competition on the specific market. The Almhult case shows how local resources can be mobilized in order to secure the best possible solution in an area, where Telia has refused to maintain their network facilities, but it is uncertain whether these resources could be mobilized without any kind of public support.

Could other policies have been used to achieve the same objective? A more strict regulation with regard to universal service might have forced Telia to provide access without any financial support. This would not necessarily result in a fibre based solution, as Telia could choose to go for a cheaper alternative. Fibre investments either facilitated or directly financially supported by the public may block investments in cheaper alternatives such as wireless networks.

In Denmark it has been suggested to use a kind of operator model, where all operations are outsourced to a private operator. Investments in public owned 
networks have not been on the agenda. The reason is to minimize market distortion and remain technology neutral.

Looking at the reality on the Danish and Swedish broadband markets it seems however that public investments in Sweden have facilitated rather than distorted competition. Provision of a public passive network infrastructure has helped independent service providers to get access to rural market segments, where competition most often is limited or non-existing.

In Denmark it is likely that almost complete coverage of broadband can be achieved without use of developmental policies. A developmental approach may speed up the process and also improve access to high capacity networks in the long run. Still the Swedish model will be relevant only in a few selected areas. However in these areas the Swedish approach can provide inspiration to how a co-operation model can be used as an alternative to a plain financial support with a complete outsourcing of all operations to a private telecom operator. The newly established broadband fund allows for this kind of initiatives.

\section{References}

[1] Danish Business Authority. (2013). Økonomiske nøgletal for telebranchen.

[2] Denmarks Radio. (2015). The liberal party will ensure full coverage of fast Internet and close hole in mobile coverage (Venstre vil sikre alle hurtigt internet og udrydde mobilhuller) 5 April 2015. Available at: http://www.dr.dk/Nyheder/Politik/2015/03/27/145024.htm

[3] Dreier, P. (1996). Community empowerment strategies: the limits and potential of community organizing in urban neighborhoods. Cityscape, 2, 121-159.

[4] EU. (2013). EU Guidelines for the application of State aid rules in relation to the rapid deployment of broadband networks (2013/C 25/01) Brussels, European Commission.

[5] Falch, M. and Henten, A. (2008). Investment dimensions in a universal service perspective: Next generation networks, alternative funding mechanisms and public-private partnerships. Info, 10, 33-45.

[6] Forzati, M. and Mattsson C. (2014) "Sweden," in The Dynamics of Broadband Markets in Europe, eds. W. Lemstra and W. H. Melody (Cambridge: Cambridge University Press).

[7] Gómez-Barroso, J. L., and Feijóo, C. (2010). A conceptual framework for public-private interplay in the telecommunications sector. Telecommun. Policy, 34, 487-495. 
[8] Helby Petersen, O. (2011). Public-Private Partnerships: Policy and Regulation-With Comparative and Multi-level Case Studies from Denmark and Ireland. Copenhagen Business School Copenhagen Business School, Department of Business and Politics Department of Business and Politics.

[9] Henten, A., and Falch, M. (2014). "The future of telecom regulation: The case of Denmark," in Paper presented at ITS, Bruxelles, Belgium.

[10] ITU (2013). Developing successful Public-Private Partnerships to foster investment in universal broadband networks. ITU, Geneva.

[11] Johnson, C. (1982) MITI and the Japanese miracle: the growth of industrial policy: 1925-1975 (Stanford: Stanford University Press).

[12] Lattemann, C., Stieglitz, S., Kupke, S., and Schneider, A. M. (2009). Impact of PPPs to broadband diffusion in Europe. Trans. Gover. People Process Policy 3, 355-374.

[13] Majone, G. (1997). From the positive to the regulatory state: causes and consequences of changes in the mode of governance. J Public Policy, 17, 139-167.

[14] Melody, W. H. (2013). Moving beyond liberalization: stumbling toward a new European ICT policy framework. Info, 15, 25-38.

[15] OECD Broadband Portal. (n.d.). Available at: http://www.oecd.org/sti/ broadband/oecdbroadbandportal.htm [last visited February 2016].

[16] Petersen, O. H. (2010). Regulation of public-private partnerships: the Danish case. Public Money Manage. 30, 175-182.

[17] Regeringskansliet. (2014). Broadbands Strategy for Sweden (Bredbandsstrategi för Sverige). Available at: https://ec.europa.eu/digitalagenda/en/news/broadband-strategy-sweden

[18] Spiller, P. T., and Tommasi, M. (2008). "The Institutions of Regulation: an application to public utilities," in Handbook of New Institutional Economics (Berlin Heidelberg: Springer), 515-543.

[19] Stiglitz, J. E. (1998, October). Towards a new paradigm for development. United Nations Conference on Trade and Development.

[20] Van Dijk, M. P. (2008). Public-private partnerships in basic service delivery: impact on the poor, examples from the water sector in India. Int. J. Water, 4, 216-234.

[21] Van der Wee, M., Mattsson, C., Raju, A., Braet, O., Nucciarelli, A., Sadowski, B., Verbruggre, S. and Pickavet, M. (2011). "How to measure the success rate of fiber-based access networks? Evaluation of the Stokab case and comparison to other European cases," In 2011 50th IEEE FITCE Congress (FITCE), 1-6. 


\section{Biographies}



M. Falch is Associate Professor at Center for Communication, Media and Information Technologies (CMI) located at Aalborg University Copenhagen. He holds a bachelor in Mathematic, a master degree in economics and a Ph.D. and has since 1988 specialised in research on socio-economic issues related to Information and Communication technologies.

He has participated in 40 research projects in the telematics area more than a third of these have been funded by EU. He has also conducted a large number of consultancies for national and international organisations such as ITU, UNCTAD, the World Bank and the National Telecom Agencies in Denmark, Norway and Sweden.

He has authored almost 200 research publications including journal papers, book chapters and research reports and conference papers. He is Editor-in-Chief of International Journal of E-Services and Mobile Applications (IJESMA) published by IGI Global. He has organised international conferences for organisations like International Telecommunications Society (ITS) and European Communication Policy Research Organisation (EuroCPR).

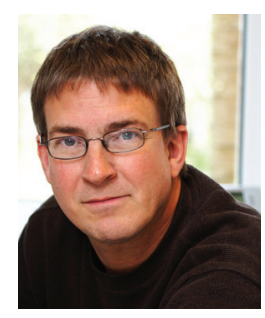

A. Henten is Professor at center for Communication, Media and Information technologies (CMI) at the Department of Electronic Systems at Aalborg University in Copenhagen. $\mathrm{He}$ is a graduate in communications 
and international development studies from Roskilde University in Denmark (1989) and holds a Ph.D. from the Technical University of Denmark (1995). He has worked professionally in the area of communications economy and policy for more than 25 years. He has participated in numerous research projects financed e.g. by the European Community, the Nordic Council of Ministers, Danish Research Councils and Ministries, and in consultancies, financed by World Bank, UNCTAD, ITU, Danish Ministries, etc. He has published nationally and internationally - more than 250 academic publications in international journals, books, conference proceedings, etc.



R. Tadayoni (born 1962) is associate professor at CMI (Center for Communication, Media and Information Technologies) at Aalborg University. He holds a M.Sc.E.E. from DTU (Danish Technical University) specialized in broadband communication, and holds a Ph.D. from DTU in the field of media convergence. His main research focus is on the ICT development and media convergence. Reza Tadayoni has participated in a number of Danish, European and international research projects and he has supervised a number of Ph.D. projects and master and bachelor thesis, and he has published +100 of scientific papers and research reports. 




I. Williams is an Adjunct lecturer at Center for Communication, Media and Information Technologies (CMI) located at Aalborg University Copenhagen. He holds a Bachelor in Physics, a Master degree in Information and Communications Technologies and a Ph.D. He has since 2010 researched into socio-economic, socio-technical related to Information and Communications Technologies. His main research focus however is in the facilitation of telecom infrastructure using Public Private Partnerships.

He has authored more than 20 research publications, including journal papers, books, book chapters, conference papers and magazine articles. $\mathrm{He}$ is the co-editor of the Book, The African Mobile Story. He has organized conferences like the CMI annual conference and the CMI/GTUC conferences. 
